\title{
Towards better healthcare for migrant and refugee children in Europe
}

\author{
Albertine Baauw ${ }^{1,2} \cdot$ Nicole Ritz ${ }^{3,4}$
}

Published online: 10 November 2017

(C) Springer-Verlag GmbH Germany 2017

On a daily basis throughout Europe, paediatricians care for children and adolescents who have been forced to leave their home countries. The marked increase in the number of migrant and refugee children we are confronted with is unprecedented, and this challenges our daily practice and mindsets. In 2016, over 1.2 million people applied for asylum in 32 European countries, of which one third were children and adolescents below the age of 18 years [6]. Migrant and refugee children are particularly vulnerable and have specific health needs $[2,4]$. These result from unfavourable conditions in their countries of origin, their flight from their home countries as well as new and unfamiliar surroundings in the countries of arrival [1].

Health systems and health care workers have been caught unaware and rather unprepared for this new challenge. The health needs of migrant and refugee children arriving at private practices, hospitals and ad hoc build-up medical centres

This Editorial refers to the article https://doi.org/10.1007/s00431-0173027-4

\section{Albertine Baauw \\ abaauw@ rijnstate.nl}

1 Department of Pediatrics, Rijnstate Hospital, Arnhem, The Netherlands

2 Department of Pediatrics and Public Health, VU University Medical Center and Academic Medical Centre, University of Amsterdam, Amsterdam, The Netherlands

3 Migrant Health Service, Paediatric Infectious Diseases and Vaccinology Unit and Paediatric Pharmacology and Pharmacometrics, University of Basel Children's Hospital, Basel, Switzerland

4 Department of Paediatrics, The University of Melbourne, Parkville, VIC, Australia challenged professionals on countless levels: communication skills, flexibility, medical knowledge, public health systems and principles [5].

A few years have elapsed since the start of the dramatic increase in migrant and refugee children arriving in Europe in 2014. It is now time to reflect. As such, the editorial board of the European Journal of Paediatrics invited the Committee of International Child Health of the Dutch Association of Paediatrics to arrange a series on migrant health in children. The efforts of numerous health care workers across Europe have not passed unnoticed. For this series, we could invite however only a few groups who are dedicated and passionate about working with this population in different European countries. The aim or the series is to promote the understanding of health needs of migrant and refugee children, and to provide health care workers with practical tools with an emphasis on a multidisciplinary approach. The series also serves to offer an insight to the organisation of public health services.

Articles are planned for publication at regular intervals over the next year. The first article published in this edition focuses on the mental health of refugee children and adolescents including the availability and usefulness of current screening and intervention tools to address their mental health needs [3]. In the following, we will have several articles such as a report from Médecins Sans Frontières (MSF) on the effect of the on-going war on physical and mental health of Syrian children. It is written by health care workers who risk their lives to deliver care to children in the most unfavourable conditions and describes the difficulties encountered in collecting health data in such extraordinary conditions. Health care workers from Médecins Du Monde (Doctors of the World) examine the barriers to access health care in 12 countries in Europe and explore the health needs of migrant and refugee families. German paediatricians will describe obstacles to delivering medical care in the context of a country that has taken 
in an exceptionally high number of refugee children. Based upon their on-the-ground experience, they offer potential solutions. The Dutch Paediatric Surveillance Unit will report on the logistical challenges and potential solutions for paediatricians caring for migrant and refugee children. In a further article, the added challenge faced by undocumented children in accessing health care, education and a home in the Netherlands is described to raise awareness for their basic rights. An article from Denmark on the organisation of public health services for refugee children and adolescents is also included as well as a consensus statement of the European Academy of Paediatrics detailing standards of health care for migrant and refugee children.

With this set of articles, we respectfully request for the betterment of health to improve the lives of some of the world's most vulnerable individuals. We hope these articles will encourage and inspire all of us to act in concert and continue our important work.

\section{References}

1. Devakumar D, Birch M, Rubenstein LS, Osrin D, Sondorp E, Wells JC (2015) Child health in Syria: recognising the lasting effects of warfare on health. Confl Health 9:34

2. Fazel M, Reed RV, Panter-Brick C, Stein A (2012) Mental health of displaced and refugee children resettled in high-income countries: risk and protective factors. Lancet 379:266-282

3. Horlings A, Hein I (2017) Psychiatric screening and interventions for minor refugees in Europe: an overview of approaches and tools. Eur J Pediatr. https://doi.org/10.1007/s00431-017-3027-4

4. Mockenhaupt FP, Barbre KA, Jensenius M, Larsen CS, Barnett ED, Stauffer W, Rothe C, Asgeirsson H, Hamer DH, Esposito DH, Gautret P, Schlagenhauf P (2016) Profile of illness in Syrian refugees: A GeoSentinel analysis, 2013 to 2015. Euro surveillance : bulletin Europeen sur les maladies transmissibles = European communicable disease bulletin 21:30160

5. Ritz N, Brinkmann F, Santiago Garcia B, Tebruegge M, Kampmann B, Paediatric Tuberculosis Network European Trials g (2015) Tuberculosis in young refugees. Lancet 386:2475-2476

6. United Nations Children's Fund (2017) A child is a child 